\title{
The effect of air pollution on inner-city children with asthma
}

\author{
K.M. Mortimer*, L.M. Neas, D.W. Dockery ${ }^{\Uparrow}$, S. Redline ${ }^{+}$, I.B. Tager ${ }^{\S}$
}

The effect of air pollution on inner-city children with asthma. K. M. Mortimer, L.M. Neas, D. W. Dockery, S. Redline, I.B. Tager. C) ERS Journals Ltd 2002.

ABSTRACT: The effect of daily ambient air pollution was examined within a cohort of 846 asthmatic children residing in eight urban areas of the USA, using data from the National Cooperative Inner-City Asthma Study.

Daily air pollution concentrations were extracted from the Aerometric Information Retrieval System database from the Environment Protection Agency in the USA. Mixed linear models and generalized estimating equation models were used to evaluate the effects of several air pollutants (ozone, sulphur dioxide $\left(\mathrm{SO}_{2}\right)$, nitrogen dioxide $\left(\mathrm{NO}_{2}\right)$ and particles with a 50\% cut-off aerodynamic diameter of $10 \mu \mathrm{m}$ (PM10) on peak expiratory flow rate (PEFR) and symptoms in 846 children with a history of asthma (ages 4-9 yrs).

None of the pollutants were associated with evening PEFR or symptom reports. Only ozone was associated with declines in morning \% PEFR $(0.59 \%$ decline $(95 \%$ confidence interval (CI) $0.13-1.05 \%$ ) per interquartile range (IQR) increase in 5-day average ozone). In single pollutant models, each pollutant was associated with an increased incidence of morning symptoms: (odds ratio $(\mathrm{OR})=1.16(95 \%$ CI $1.02-1.30)$ per IQR increase in 4-day average ozone, OR=1.32 $(95 \%$ CI 1.03-1.70) per IQR increase in 2-day average $\mathrm{SO}_{2}, \mathrm{OR}=1.48(95 \%$ CI 1.02-2.16) per IQR increase in 6-day average $\mathrm{NO}_{2}$ and $\mathrm{OR}=1.26(95 \%$ CI $1.0-1.59)$ per IQR increase in 2-day average PM10.

This longitudinal analysis supports previous time-series findings that at levels below current USA air-quality standards, summer-air pollution is significantly related to symptoms and decreased pulmonary function among children with asthma. Eur Respir J 2002; 19: 699-705.

\begin{abstract}
*Dept of Epidemiology, Harvard School of Public Health, Boston, MA, "Epidemiology and Biomarkers Branch, US Environmental Protection Agency/National Health and Environmental Effects Research Laboratory, Human Studies Division, Chapel Hill, NC, Dept of Epidemiology and Environmental Health, Harvard School of Public Health, Boston, MA, ${ }^{+}$Dept of Pediatrics, Case Western Reserve University, Rainbow Babies \& Children's Hospital, Cleveland, $\mathrm{OH}$ and ${ }^{8}$ Dept of Public Health Biology and Epidemiology, University of California, Berkeley, CA, USA.
\end{abstract}

Correspondence: K.M. Mortimer, School of Public Health, 1918 University Ave, University of California, Berkeley, CA 94720-7370, USA.

Fax: 15106430239

E-mail: kmort@uclink4.berkeley.edu

Keywords: Air pollution, asthma, generalized estimating equations, inner-city, mixed linear models

Received: July 92001

Accepted after revision December 16 2001

The NCICAS research was supported by grants U01 AI-30751, AI-30752, AI30756, AI-30772, AI-30773, AI-30777, AI-30779, AI30780, and AI-15105 from NIAID, NIH.
Much of the evidence for the effect of air pollution on respiratory health [1-8] is based on time-series analyses of repeated measurements in closed cohorts, which create a daily summary of responses across all study individuals. Fluctuations in this summary measure are evaluated relative to daily fluctuations in air pollution. Therefore, these approaches are not well suited to investigations of individual-level factors related to heterogeneity of response. Time-series analyses require that the distribution of individuallevel factors in the study population remain stable over time [9] or that data on changes in these characteristics are included in the model. This limits their usefulness in studying populations which do not remain fixed during the study period.

Longitudinal analysis techniques such as mixed linear models and generalized estimating equations provide a more statistically powerful alternative by incorporating individual level outcomes and covariates.
They permit estimation of individual mean effects and individual change over time as well as population mean effects over the entire study period. These methods require no assumptions about stability of population characteristics over time and subjects with incomplete data can be included in the analysis [10]. Therefore these methods are well-suited for epidemiological studies.

These methods were used to evaluate air pollutionrelated health effects in a large cohort of inner-city children with asthma. Individual-level risk factors that modified the response to ozone in this cohort have been reported previously [11]. In particular, it was found that asthmatic children born prematurely ( $<37$ weeks) or with a low birth weight $(<2.5 \mathrm{~kg})$ had a significantly greater response to increases in ozone. This study compares these results to time-series and other analyses and presents multipollutant models. 


\section{Design and methods}

\section{Cohort identification}

The cohort was obtained from the National Cooperative Inner-City Asthma Study (NCICAS), a multicentre study of asthmatic children in eight urban areas in the USA. Although NCICAS examined a wide range of risk factors for asthma morbidity, including access to healthcare, psychosocial problems, and the home environment, this report is limited to the association with urban air pollution. The design and methods have been reported previously [12]. Briefly, children and their parents were recruited from emergency departments and primary care clinics in eight urban areas: Bronx and East Harlem, NY; Baltimore, MD; Washington, DC; Detroit, MI; Cleveland, OH; Chicago, IL; and St. Louis, MO. Children were 4-9 yrs old and resided in inner-city neighbourhoods in which the income of $\geqslant 30 \%$ of residents was below the federal poverty level. Study children had either: 1) parental report of physiciandiagnosed asthma and symptoms in the past 12 months or 2) respiratory symptoms consistent with asthma, such as cough, wheezing or shortness of breath, that lasted $>6$ weeks during the previous year, together with increased symptoms with exercise or cold air exposure or a family history of asthma. The protocol included an in-person baseline interview, a home survey, three brief telephone follow-up interviews at three-month intervals, and two-week peak expiratory flow rate (PEFR) and symptom diaries after the baseline interview and prior to each follow-up interview. To reduce confounding by temperature and seasonal infectious disease, this analysis is restricted to those children who returned at least one diary during June-August of 1993.

\section{Exposure measures}

Air pollutant concentrations were obtained from the Aerometric Information Retrieval System of the Environmental Protection Agency in the USA. Daily pollutant metrics were calculated by averaging hourly readings for selected periods, based on peak occurrences, which are noted in the section on each pollutant. Multiday metrics were calculated by averaging these daily metrics. Children within the same urban area were assigned common daily and multiday values for each pollutant, calculated by averaging the pollutant concentrations from all monitors in the corresponding county. Single and multipollutant models are presented. Pollutants are often highly correlated, and consequently this report focuses on ozone as a good marker for summer air pollution in the NCICAS cities. Weather data were obtained from local airports.

\section{Outcome measures}

Children were trained in the use of a mini-Wright peak flow meter (Clement Clarke, Columbus, $\mathrm{OH}$,
USA). PEFR and symptoms (cough, chest tightness, wheeze) were reported in the morning upon rising, and before bedtime, prior to use of any inhaled medications. The maximum of three manoeuvres, performed while standing, was recorded. NCICAS was not an intervention and parents were not instructed on the interpretation of PEFR. Values $<70$ or $>450 \mathrm{~L} \cdot \mathrm{min}^{-1}(0.4 \%$ and $2.5 \%$ of readings, respectively) were considered to be implausible (e.g. errors in transcription) and were deleted.

Three outcome measures were evaluated separately for morning and evening: 1) daily per cent change from the diary-specific median PEFR; 2) the incidence of $\geqslant 10 \%$ decline from the diary-specific median PEFR; 3) the incidence of any symptom. Changes in PEFR (rather than mean levels) and incidence (rather than prevalence) were evaluated to focus on the impact of air-pollution level on changes in morbidity.

\section{Statistical methods}

The per cent change in PEFR was analysed using linear mixed effect models (SAS Proc Mixed [13]), while the incidence of symptoms and incidence of a $10 \%$ decline in median PEFR were modelled with generalized estimating equations, using a logistic link. Change-in-estimate criteria and likelihood ratio tests were used to determine the choice of covariates, with an alpha level of 0.05 . Akaike's Information Criteria (AIC) was used to evaluate the best correlation structure and to determine if a covariate should be entered as a fixed or random effect. Models with the AIC closest to zero were considered to best fit the data. Standard errors were insensitive to the use of several covariance structures, therefore results from models assuming the most simple structure (independence) were reported.

Lagged air pollution effects were evaluated using moving averages, unrestricted distributed lags, and polynomial distributed lags. Within-model lag-specific estimates were combined to create a cumulative effect over a specified interval and estimates were then compared across models.

\section{Results}

Approximately $60 \%$ of the children returned a diary for each of the four visits. From June-August of 1993, 846 children returned at least one diary, for a total of 910 diaries. Their characteristics were similar to the entire NCICAS cohort $(n=1528)$, although children who reported $\geqslant 2$ asthma medications in the previous three months (an indicator of asthma severity) were more likely to have returned diaries (table 1). Each diary contributed up to 14 days of readings $(11,622$ child days). Completeness of diary readings was unrelated to pollution levels during the diary period.

Pollutant and temperature distributions are presented in figure 1. Across all urban areas, the 8-h average ozone (10:00-18:00 h) was 48 parts per billion (ppb), and $<5 \%$ of days exceeded the proposed USA 
Table 1. - Demographic characteristics of National Cooperative Inner-city Asthma Study (NCICAS) children who returned at least one diary between June 1-August 31, 1993

\begin{tabular}{|c|c|c|c|c|c|c|c|c|c|}
\hline $\begin{array}{l}\text { Patient } \\
\text { characteristics }\end{array}$ & Total & Bronx & $\begin{array}{c}\text { East } \\
\text { Harlem }\end{array}$ & Baltimore & $\begin{array}{c}\text { Washington } \\
\text { DC }\end{array}$ & Detroit & Cleveland & Chicago & $\begin{array}{l}\text { St. } \\
\text { Louis }\end{array}$ \\
\hline Subjects $\mathrm{n}$ & 846 & 143 & 104 & 111 & 92 & 84 & 56 & 138 & 118 \\
\hline Diaries $n$ & 910 & 151 & 113 & 12 & 99 & 8 & 61 & 141 & 129 \\
\hline Male \% & 63 & 60 & 61 & 63 & 72 & 63 & 66 & 59 & 62 \\
\hline Black \% & 71 & 23 & 37 & 90 & 99 & 94 & 98 & 65 & 97 \\
\hline Hisp & 19 & 66 & 51 & 1 & 0 & 0 & 0 & 27 & 0 \\
\hline Severe $^{\#} \%$ & 48 & 57 & 42 & 51 & 45 & 49 & 38 & 52 & 42 \\
\hline $\begin{array}{l}\text { Morning PEFR } \\
\mathrm{L} \cdot \mathrm{min}^{-1} \text { mean } \pm \mathrm{SD}\end{array}$ & $206 \pm 72.7$ & $217 \pm 71.1$ & $211 \pm 68.5$ & $206 \pm 79.3$ & $205 \pm 67.1$ & $190 \pm 66.9$ & $193 \pm 76.8$ & $206 \pm 72.0$ & $205 \pm 75.6$ \\
\hline $\begin{array}{l}10 \% \text { decline in } \\
\text { morning PEFR }\end{array}$ & 14.1 & 13.4 & 12.8 & 13.8 & 12.7 & 13.8 & 13.2 & 14.8 & 16.9 \\
\hline Any morning symptom & 11.6 & 11.9 & 12.1 & 11.0 & 10.0 & 10.5 & 10.0 & 11.3 & 14.2 \\
\hline
\end{tabular}

${ }^{\#}$ : reported at least 2 classes of medicines at baseline; ${ }^{\circ}$ : incidence 100 child-days ${ }^{-1}$. PEFR: peak expiratory flow rate.

standard of $80 \mathrm{ppb}\left(157 \mu \mathrm{g} \cdot \mathrm{m}^{-3}\right)$ [14]. The effect estimates were scaled to a $15 \mathrm{ppb}$ increase in ozone (the approximate interquartile range, table 2). The average intradiary range in daily ozone was $48 \mathrm{ppb}$.

Models for all three outcomes included fixed effects for an ozone metric, indicators for diary number (i.e. baseline, 3 or 6-month diary), day of study (starting June 1, 1993), rain in the past $24 \mathrm{~h}$, urban area, and a linear term for 12-h average wet-bulb temperature. Including the temperature term in the model increased the magnitude of the ozone coefficient by $>30 \%$, suggesting it was a strong confounder.
Nonlinear terms for temperature had little effect on the magnitude or precision of the ozone coefficient. Modelling urban area as a fixed rather than random effect provided a better fit and did not influence the ozone estimate, nor did including a term for day of week. Daily medication use and time-activity information were not available for inclusion in the models.

No association was seen between single or multiday ozone metrics and any evening outcome measure (table 2). The effect of ozone on morning outcomes increased over several days and the strongest association was seen for multiday moving averages.
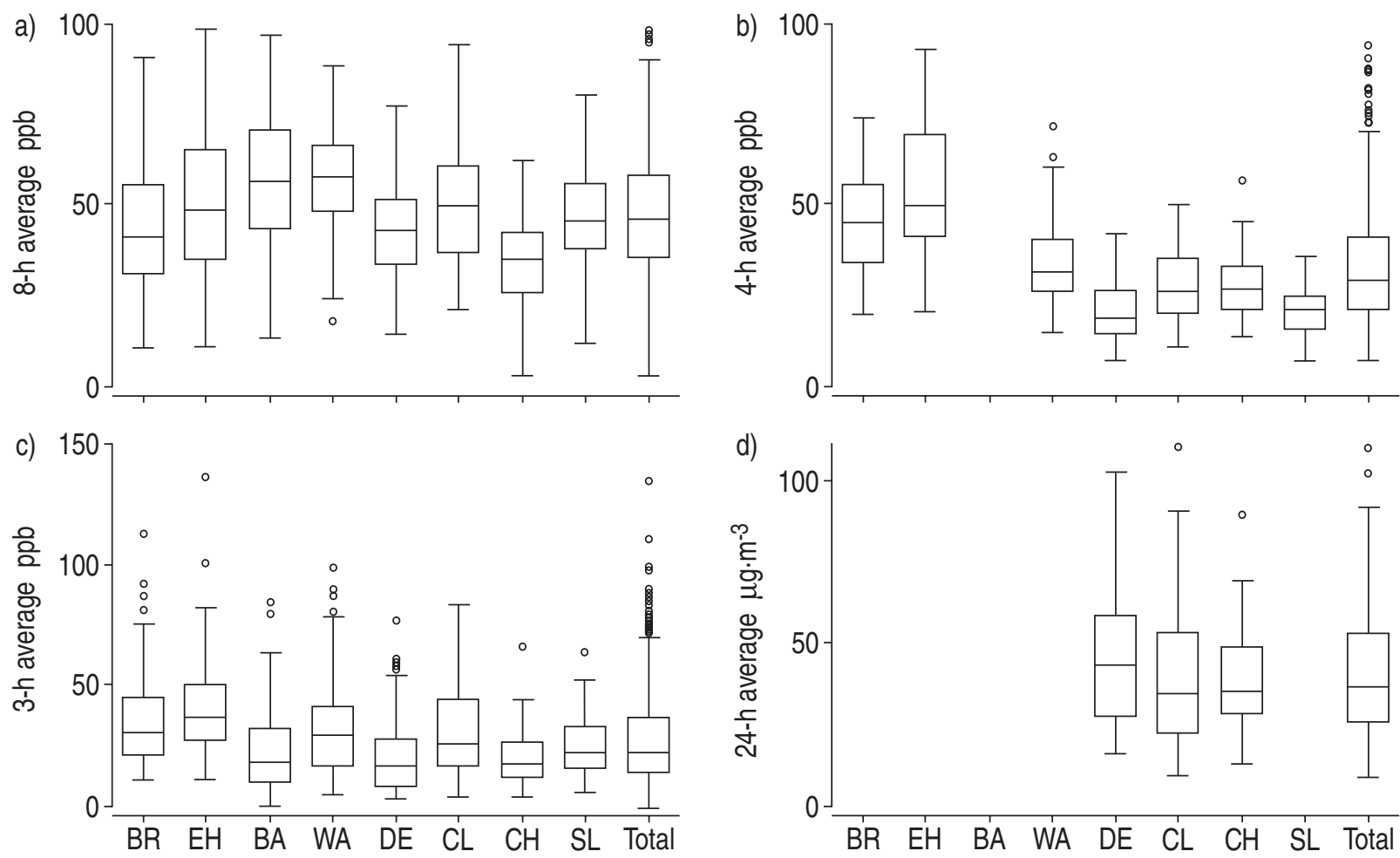

Fig. 1. - Pollutants shown by urban area a) ozone, b) nitrogen dioxide, c) sulphur dioxide and d) particles with a $50 \%$ cut-off aerodynamic diameter of $10 \mu \mathrm{m}$. Boxes extend from the 25 th to 75 th percentile (Interquartile range (IQR)). The lines extend to lower and upper adjacent values, defined as three halves of the IQR. Circles represent days more extreme than the adjacent values. BR: Bronx; EH: East Harlem; BA: Baltimore; WA: Washington; DE: Detroit; CL: Cleveland; CH: Chicago; SL: St Louis; ppb: parts per billion. 
Table 2. - Effect of a 15 parts per billion increase in ambient ozone concentration on peak expiratory flow rate (PEFR) and asthma symptoms in 8 urban areas of the National Cooperative Inner-city Asthma Study (NCICAS) June 1-August 31, 1993

\begin{tabular}{lccc}
\hline Measures & PEFR $^{\#} \%$ change $(95 \%$ CI) & Incidence of $\geqslant 10 \%$ decline in PEFR & Incidence of symptoms $^{\#}$ \\
\hline Morning measures & & & \\
Lag 1 & $-0.06(-0.38-0.26)$ & $1.04(0.97-1.12)$ & $1.03(0.94-1.12)$ \\
Lag 2 & $-0.13(-0.40-0.15)$ & $1.04(0.98-1.11)$ & $1.10(1.02-1.19)$ \\
Lag 3 & $-0.32(-0.59-0.05)$ & $1.04(0.97-1.10)$ & $1.01(0.94-1.09)$ \\
Lag 4 & $-0.22(-0.48-0.05)$ & $1.09(1.02-1.16)$ & $0.99(1.01-1.17)$ \\
Lag 5 & $-0.22(-0.49-0.05)$ & $1.03(0.97-1.10)$ & $0.97(0.90-1.07)$ \\
Lag 6 & $0.07(-0.20-0.33)$ & $0.97(0.91-1.03)$ & $1.16(1.02-1.30)$ \\
Average, lag 1-5 & $-0.59(-1.05-0.13)$ & $1.14(1.02-1.27)$ & \\
Average, lag 1-4 & & $1.00(0.89-1.13)$ & $1.02(0.88-1.18)$ \\
Evening measures & $-0.05(-0.51-0.41)$ & & \\
$\quad$ Average, lag 0-4 & & & \\
Average, lag 0-3 & & & \\
\hline
\end{tabular}

Data are presented as odds ratio with $95 \%$ confidence intervals in parentheses unless otherwise stated. ${ }^{*}$ : Adjusted for day of study, previous 12-h mean wet-bulb temperature, urban area, diary number, rain in the past $24 \mathrm{~h}$, with an independence covariance structure.

A $15 \mathrm{ppb}$ increase in 5-day moving average ozone was associated with a $0.59 \%$ decline in morning PEFR $(95 \%$ CI $0.13-1.05)$ and with the incidence of $\mathrm{a} \geqslant 10 \%$ decline in morning PEFR (OR=1.14, 95\% CI 1.02 1.27). The incidence of morning symptoms was most strongly associated with a 4-day moving average $(\mathrm{OR}=1.16$, 95\% CI 1.02-1.30.) The effect of the corresponding multiday lags on each evening outcome is presented for comparison purposes (i.e. average of lag $0-4$ for evening measures can be compared to the average of lag 1-5 for morning measures).

For morning PEFR, cumulative effects from unrestricted lag, second degree polynomial distributed lag, and moving average models were nearly identical (cumulative declines $=0.54 \%, 0.51 \%$, and $0.59 \%$ ). Unrestricted lag models suggested that the ozone exposures from 3-5 days prior have a greater impact on morning \%PEFR than more immediate exposures. The 5-day average (lags 1-5) showed a slightly greater effect than a 3-day average (lags 3-5) or 4-day average (lags 2-5) (data not shown), despite the fact that the estimates from models using lags 1 and 2 suggested little increased risk. For morning symptoms, unrestricted lag, polynomial distributed lag, and moving average models yielded similar cumulative estimates $(\mathrm{OR}=1.13,1.14,1.14$, respectively).

Excluding days when ozone was $>80 \mathrm{ppb}$ (proposed US Federal Standard) provided estimates which were nearly identical findings to those obtained using all of the days $(0.70 \%$ decline in PEFR $(95 \%$ CI $0.12-$ $1.29 \%), \mathrm{OR}=1.15(95 \%$ CI $0.99-1.33)$ for a $10 \%$ decline in morning PEFR, OR=1.17 (95\% CI 1.01-1.35) for the incidence of morning symptoms).

The consistency of urban area-specific estimates was evaluated by adding an "ozone by urban area" interaction term to each model. Interaction terms were null. In fact, with the exception of the Baltimore centre, the estimates for morning \%PEFR were strikingly similar across urban areas (table 3 ). In all areas except St. Louis, the increase in ozone was associated with an increase in the incidence of morning symptoms.

The number of ozone monitors per urban area ranged from 1-13. Analyses were repeated using the average of readings from up to the three closest monitors to the centre of the child's zipcode [15], and

Table 3. - Estimated effect of a 15 parts per billion increase in ambient ozone on peak expiratory flow rate (PEFR) and asthma symptoms for each National Cooperative Inner-city Asthma Study (NCICAS) urban area

\begin{tabular}{lccc}
\hline Urban area & $\begin{array}{c}\text { Morning \% PEFR } \\
\% \text { change }\end{array}$ & $\begin{array}{c}\text { Incidence of } \geqslant 10 \% \\
\text { decline in morning PEFR }\end{array}$ & $\begin{array}{c}\text { Incidence of } \\
\text { morning symptoms }\end{array}$ \\
\hline Bronx & $-0.69(-1.54-0.15)$ & $1.10(0.90-1.34)$ & $1.23(0.98-1.54)$ \\
East Harlem & $-0.73(-1.63-0.17)$ & $1.15(0.90-1.48)$ & $1.22(0.97-1.53)$ \\
Baltimore & $0.24(-0.95-1.43)$ & $1.37(1.09-1.72)$ & $1.19(0.89-1.60)$ \\
Washington, D.C & $-0.54(-2.02-0.93)$ & $0.95(0.68-1.33)$ & $1.11(0.72-1.72)$ \\
Detroit & $-0.75(-2.36-0.86)$ & $1.24(0.91-1.68)$ & $1.72(1.12-2.64)$ \\
Cleveland & $-0.62(-2.23-0.99)$ & $1.31(0.87-1.97)$ & $1.20(0.81-1.79)$ \\
Chicago & $-0.62(-2.41-1.16)$ & $1.18(0.77-1.80)$ & $1.09(0.69-1.72)$ \\
St. Louis & $-0.86(-2.10-0.38)$ & $0.99(0.73-1.34)$ & $0.82(0.59-1.14)$ \\
All urban areas & $-0.59(-1.05-0.13)$ & $1.14(1.02-1.27)$ & $1.16(1.02-1.30)$ \\
\hline
\end{tabular}

Data are presented as odds ratio with $95 \%$ confidence intervals in parentheses unless otherwise stated. *: Models include day of study, previous 12-h mean temperature, urban area, diary number, rain in the past $24 \mathrm{~h}$, ozone and "ozone by urban area" interaction term, with an independence covariance structure; $"$ : 5-day average ozone for $\% \mathrm{PEF}$ and $10 \%$ declines in PEF, 4-day average ozone for symptoms. 
the findings were similar $(0.50 \%$ decline in $\%$ PEFR and symptom $\mathrm{OR}=1.15$.)

\section{Co-pollutants}

Sulphur dioxide $\left(\mathrm{SO}_{2}\right)$, nitrogen dioxide $\left(\mathrm{NO}_{2}\right)$, and particles with a $50 \%$ cut-off aerodynamic diameter of $10 \mu \mathrm{m}$ (PM10) were evaluated using models similar to the ozone models described earlier. Estimates for evening effects were null (data not shown). Only morning \%PEFR and symptom incidence findings are presented (table 4).

Daily $\mathrm{SO}_{2}$ data were available for all eight urban areas, with an average intradiary range of $53 \mathrm{ppb}$. The correlation between 8-h ozone and 3-h mean (08:00 11:00 h) $\mathrm{SO}_{2}$ was 0.29 . Single-pollutant models suggest that single and multiday lags of $\mathrm{SO}_{2}$ had little effect on morning \%PEFR (data not shown). The greatest effect on morning symptoms was seen for a 2-day moving average lag (table 4). Results were similar for 3 and 4-day moving averages. When 5-day average ozone and 2-day average $\mathrm{SO}_{2}$ were entered in a model simultaneously, there was essentially no impact on the estimate for $\mathrm{SO}_{2}$ while the estimate for ozone decreased slightly.

Daily $\mathrm{NO}_{2}$ was available in seven urban areas (nearly 10,000 child days), with an average intradiary range of $32 \mathrm{ppb}$. The correlation between 8 -h mean ozone and 4-h $\mathrm{NO}_{2}(06: 00-10: 00 \mathrm{~h})$ was 0.27 . $\mathrm{NO}_{2}$ was not associated with declines in \%PEFR and the greatest effect on morning symptoms was for a 6-day moving average. Joint modelling of $\mathrm{NO}_{2}$ and ozone slightly reduced the estimates for each pollutant.

Daily PM10 was measured only in Chicago, Cleveland and Detroit ( $>3,000$ child days, ) with an average intradiary range of $53 \mu \mathrm{g} \cdot \mathrm{m}^{-3}$. The correlation between 24-h average PM10 and 8-h average ozone was 0.51 . Although there were no statistically significant effects of PM10 on morning \%PEFR, estimates were negative and of similar magnitude to those found for ozone $\left(0.89 \%\right.$ decline per $25 \mu \mathrm{g} \cdot \mathrm{m}^{-3}$ increase in 6-day moving average, 95\% CI $-0.54-2.31 \%$ decline). Significant effects on evening \%PEFR were found only at much greater lags (8 days). None of the lags of PM10 were associated with the incidence of evening symptoms. In a single-pollutant model, the strongest association with morning symptoms was seen for a 2-day average. Entering PM10 and ozone in the model simultaneously resulted in a slight reduction in the PM10 estimate, but a larger reduction in the ozone estimate and wider confidence intervals (table 4).

Each individual pollutant was associated significantly with an increase in the incidence of morning symptoms. Multiday lags with the strongest associations in each of the single-pollutant models were simultaneously entered into a model. When restricted to the seven urban areas with complete data for ozone, $\mathrm{SO}_{2}$ and $\mathrm{NO}_{2}$, only $\mathrm{SO}_{2}$ remained significantly associated with morning symptoms. Models with all four pollutants were restricted to the three urban areas with complete data. Estimates for most pollutants were positive, however the confidence intervals were wide due to the substantially smaller sample size and colinearity among pollutants.

\section{Discussion}

This study provides evidence of measurable negative respiratory health effects in children from eight inner-city communities in northeastern and midwestern USA. Direct comparisons to estimates reported in other studies are difficult, due to variations in outcome measures, analytical techniques and exposure definitions. A time-series analysis of 61 asthmatic children [8] in the Netherlands reported results corresponding to a $0.4 \%$ decline in PEFR and $\mathrm{OR}=1.03$ per $15 \mathrm{ppb}$ of ozone. Similarly, a summer camp study of asthmatic children in Connecticut [16] observed effects comparable to a $0.5 \%$ decline in PEFR per $15 \mathrm{ppb}$ increase in ozone, despite much higher average ozone concentrations. Smaller effects were found among a group of 71 asthmatic children in

Table 4. - Single and multipollutant models for the incidence of morning asthma symptoms National Cooperative Inner-city Asthma Study (NCICAS)

\begin{tabular}{|c|c|c|c|c|}
\hline Model $^{\#}$ & $\begin{array}{l}\text { Ozone Average } \\
\text { of lag } 1-5\end{array}$ & $\begin{array}{c}\mathrm{SO}_{2} \text { Average } \\
\text { of lag 1-2 }\end{array}$ & $\begin{array}{c}\mathrm{NO}_{2} \text { Average } \\
\text { of lag 1-6 }\end{array}$ & $\begin{array}{l}\text { PM10 Average } \\
\text { of lag } 1-2\end{array}$ \\
\hline \multicolumn{5}{|l|}{ All 8 urban areas } \\
\hline Single pollutant & $1.16(1.02-1.30)$ & $1.19(1.06-1.35)$ & & \\
\hline Ozone $+\mathrm{SO}_{2}$ & $1.11(0.97-1.27)$ & $1.18(1.05-1.33)$ & & \\
\hline \multicolumn{5}{|l|}{7 urban areas } \\
\hline Single pollutant & $1.12(0.97-1.30)$ & $1.22(1.07-1.40)$ & $1.48(1.02-2.16)$ & \\
\hline Ozone $+\mathrm{NO}_{2}$ & $1.07(0.92-1.26)$ & & $1.40(0.93-2.09)$ & \\
\hline Ozone $+\mathrm{SO}_{2}+\mathrm{NO}_{2}$ & $1.06(0.90-1.25)$ & $1.19(1.04-1.37)$ & $1.31(0.87-2.09)$ & \\
\hline \multicolumn{5}{|l|}{3 urban areas ${ }^{+}$} \\
\hline Single pollutant & $1.10(0.78-1.55)$ & $1.32(1.03-1.70)$ & $1.70(0.77-3.74)$ & $1.26(1.00-1.59)$ \\
\hline Ozone+PM10 & $1.04(0.70-1.55)$ & & & $1.25(0.97-1.61)$ \\
\hline Ozone $+\mathrm{SO}_{2}+\mathrm{NO}_{2}+\mathrm{PM} 10$ & $1.00(0.75-1.34)$ & $1.23(0.94-1.62)$ & $1.45(0.63-3.34)$ & $1.14(0.80-1.48)$ \\
\hline
\end{tabular}

Data are presented as odds ratio with $95 \%$ confidence intervals in parentheses. ${ }^{*}$ : Adjusted for day of study, previous $12-\mathrm{h}$ mean temperature, urban area, diary number, rain in the past $24 \mathrm{~h}$, with an independence covariance structure; ${ }^{\top}: \mathrm{NO}_{2}$ data were not available in Baltimore; ${ }^{+}$: Daily PM10 were collected in Chicago, Cleveland and Detroit. For the odds ratio estimates are rescaled to an interquartile range change (20 ppb for $\mathrm{SO}_{2}$ and $\mathrm{NO}_{2}, 20 \mu \mathrm{g} \cdot \mathrm{m}^{-3}$ for particles with a $50 \%$ cut-off aerodynamic diameter of $10 \mu \mathrm{m}$ (PM10), $15 \mathrm{ppb}$ for ozone). $\mathrm{SO}_{2}$ : sulphur dioxide; $\mathrm{NO}_{2}$ : nitrogen dioxide. 
Mexico City [3], with no effect on PEFR and OR=1.03 for symptoms per $15 \mathrm{ppb}$ increase in ozone. In each of these studies, effects were found over shorter intervals (0-2 day lags) than in the NCICAS population (4-5 day moving average). In contrast to other findings $[1,3,17]$, current day effects were not found in the NCICAS cohort. Instead, the strongest associations were seen with multiday moving averages. Other studies have also reported larger estimates from moving day average exposures than those based on single-day exposures [18, 19, 20]. The Pollution Effects on Asthmatic Children in Europe (PEACE) study [21] did not see an effect of winter pollutants and presented data based on shorter lags. These differences, as well as possible differences in population characteristics that modify the response to pollution may account for the contradictory results [10]. Findings in these USA inner-city asthmatic children are comparable to findings reported elsewhere, suggesting the magnitude of the air pollution-related effect on asthma morbidity is not substantially greater in this population in relation to more socioeconomically diverse groups of asthmatic children. The baseline risk for asthma morbidity may be higher in these communities and, therefore air pollution may contribute substantially to the burden of asthma morbidity.

Small declines in PEFR may be of questionable clinical significance. There were, however, significant associations with the incidence of $\geqslant 10 \%$ declines in PEFR and symptoms that clearly have clinical importance to asthma morbidity [22]. The consistency of these effects suggests that despite known limitations [23], the peak flow data effectively captured important decrements in pulmonary function. Nondifferential misclassification of outcome and exposure data may have contributed to an underestimate of the effects. Also, a report published previously [10] has identified subgroups with more clinically important responses to air pollution. Future analyses of the health effects of air pollution would benefit from the inclusion of individual-level risk factors, which can greatly modify the size of the health effect.

The effects on PEFR and symptoms were limited primarily to morning measures. Morning values are better indicators of asthmatics who are susceptible to airway narrowing [24], and, therefore, focusing on morning measures may identify children at greater risk for adverse health outcomes. The most severe bronchoconstriction occurs in the morning, when measurable differences between and within individuals may be greatest. Alternatively, the lack of association with evening measures may be due to the use of asthma medication during the day, which may attenuate the association with air pollution and daily peak flow and symptom reports $[1,25]$. The lack of evening effects may reflect misclassification due to an inability to adjust for time the child spent outdoors or exercising, both of which affect respiratory dose [26]. Controlling for these factors may improve the estimates [4].

Only three of the urban areas had daily PM10 monitors, making the sample size too small to allow for unambiguous assessment of multipollutant models. In these three cities, however, a stronger association was seen for PM10 than ozone, and, as others have reported PM10 was more strongly associated with asthma symptoms rather than PEFR [3]. Delfino et al. [1] reported that 8-h maximum PM10 was more highly associated with morbidity than the 24-h PM10 measurements. It was not possible to test that hypothesis with existing monitoring data.

Biological mechanisms for delayed effects on pulmonary function include increased bronchial reactivity secondary to airway inflammation associated with irritant exposures. Animal and chamber studies suggest that exposure to air pollution may augment airway cellular infiltration and cellular activation, enhance release of cytotoxic inflammatory mediators, alter membrane permeability, and alter mucociliary clearance [27-29]. Given the lengthy lag times for ozone, $\mathrm{PM} 10$ and $\mathrm{NO}_{2}$ effects, ambient pollutants may not only be acting as a direct trigger of asthma attacks, but may also act indirectly as a primer for a subsequent antigen exposure [30,31]. While ozone was most influential on PEFR, $\mathrm{NO}_{2}$ had the strongest effect on symptoms. $\mathrm{NO}_{2}$ may be a better marker for the summer-pollutant mix in these cities, largely east of the Mississippi, in that it is related to the photochemistry of ozone and the emissions of hydrocarbons that accompany particle pollutants released from automobiles.

These findings are not likely to be confounded by asthma risk factors such as allergen sensitization and housing characteristics since they do not vary within the two-week monitoring interval. Medication or air conditioner use and exposure to tobacco smoke may vary daily, however, those data were not available. The similarity of the quantitative group mean estimates to those from time-series analyses discussed earlier, however, suggests that confounding does not explain the results.

In conclusion, summer-time air pollution is associated with increased asthma morbidity and decreased pulmonary function among inner-city children with asthma in the USA. These findings from generalized estimating equations and mixed models support previously published reports from time-series analysis, and those reported from less urban populations. The impact of pollution was not immediate, but developed over several days, with the largest effects seen on morning outcomes. Nitrogen dioxide, sulphur dioxide, and particles with a 50\% cut-off aerodynamic diameter of $10 \mu \mathrm{m}$ were associated with increases in symptoms, with nitrogen dioxide exhibiting the strongest influence. Ozone was most influential on peak expiratory flow rate. Adverse respiratory effects were observed in all cities, at levels below proposed USA air quality standards.

\footnotetext{
Acknowledgements. The authors would like to thank the NCICAS staff and participants, whose hard-work and cooperation made this study possible, L. Ngo for his expert statistical advice and M. Aggarwal for geocoding the addresses and providing the monitor selection data.

The contents of this report are solely the responsibility of the authors and do not
} 
necessarily represent the official views of the Environmental Protection Agency (EPA). The research described in this article has been subject to EPA's peer and administrative review and it has been approved for publication.

\section{References}

1. Delfino FJ, Zeiger RS, Seltzer JM, Street DH. Symptoms in pediatric asthmatics and air pollution: differences in effects by symptom severity, anti-inflammatory medication use and particulate averaging time. Environ Health Perspect 1998; 106: 751-761.

2. White MC, Etzel RA, Wilcox WD, Lloyd C. Exacerbations of childhood asthma and ozone in pollution in Atlanta. Environ Res 1994; 65: 56-68.

3. Romieu I, Meneses F, Ruiz S, et al. Effects of air pollution on the respiratory health of asthmatic children living in Mexico City. Am J Respir Crit Care Med 1996; 154: 300-307.

4. Neas LM, Dockery DW, Burge H, Koutrakis P, Speizer F. The association of ambient air pollution with twice daily peak expiratory flow rate measurements in children. Am J Epidemiol 1995; 141: 111-122.

5. Ostro B, Lipsett M, Wiener M, Pham D, Selner J. Asthmatic responses to airborne acid aerosols. Am J Public Health 1991; 81: 694-702.

6. Avol EL, Navidi WC, Rappaport EB, Peters JM. Acute effects of ambient ozone on asthmatic, wheezy and healthy children. Research Report Number 82. Cambridge, MA, Health Effects Institute, 1998.

7. Scanell C, Chen L, Aris RM, et al. Greater ozoneinduced inflammatory responses in subjects with asthma. Am J Respir Crit Care Med 1996; 154: 24-29.

8. Gielen $\mathrm{MH}$, van der Zee SC, van Wijnen $\mathrm{JH}$, van Steen CL, Brunekreef B. Acute effects of summer air pollution on respiratory health of asthmatic children. Am J Respir Crit Care Med 1997; 155: 2105-2108.

9. Chatfield C. The analysis of time series. 5th Edn. London/New York, Chapman and Hall, 1996.

10. Diggle PJ, Liang KY, Zeger ST. Analysis of longitudinal data. New York, Oxford University Press Inc, 1994.

11. Mortimer KM, Tager I, Dockery D, Neas L, Redline S. The Effect of ozone on inner-city children with asthma: identification of susceptible subgroups. Am J Respir Crit Care Med 2000; 162: 1838-1845.

12. Mitchell HE, Senturia Y, Gergen P, et al. Design and methods of the National Cooperative Inner-City Asthma Study. Pediatric Pulmonology 1997; 24: 237252.

13. Littell RC, Milliken GA, Stroup WW, Wolfinger RD. SAS System for Mixed Models. Cary NC, SAS Institute Inc., 1996.

14. Federal Register 1997. National Ambient Air Quality Standards for Ozone: Final Rule. Fed Reg 62: 1-37 40 CFR Part 50, 1997.

15. Kinney PL, Aggarwal M, Nikiforov SV, Nadas A. Methods development for epidemiologic investigations of the health effects of prolonged ozone exposures, Part III. An approach to retrospective estimation of lifetime ozone exposures using a questionnaire and ambient monitoring data (US Sites).
Research report number 81. Cambridge, MA, Health Effects Institute, 1998.

16. Thurston GD, Lippman M, Scott MB, Fine JM. Summertime haze air pollution and children with asthma. Am J Respir Crit Care Med 1997; 155: 654 660.

17. Kinney PK, Thurston GD, Raizenne M. The effects of ambient ozone on lung function in children: a reanalysis of six summer camp studies. Environ Health Perspect 1996; 104: 170-174.

18. Gold D, Damokosh AI, Pope CA, et al. Particulate and ozone pollutant effects on the respiratory function of children in southwest Mexico City. Epidemiology 1999; 10: 8-16.

19. Spektor DM, Thurston GD, Mao J, He D, Hayes C, Lippmann M. Effects of single- and multi-day ozone exposures on respiratory function in active normal children. Environ Res 1991; 55: 107-122.

20. Schwartz J, Dockery DW, Neas LM, et al. Acute effects of summer air pollution on respiratory symptom reporting in children. Am J Respir Crit Care Med 1994; 150: 1234-1242.

21. Roemer W, Hoek G, Brunekreef B. Pollution effects on asthmatic children in Europe, the PEACE study. Clin Exp Allergy 2000; 30: 1067-1075.

22. Hoek G, Dockery DW, Pope A, Neas L, Roemer W, Brunekreef B. Association between PM10 and decrements in peak expiratory flow rates in children: reanalysis of data from five panel studies. Eur Respir $J$ 1998; 11: 1307-1311.

23. Redline S, Wright E, Kattan M, Kercsmar C, Weiss $\mathrm{K}$. Short-term compliance with peak flow monitoring: results from a study of inner city children with asthma. Pediatr Pulmonol 1996; 21: 203-210.

24. National Heart, Lung, and Blood Institute. National asthma education and prevention program, expert panel report 2: Guidelines for the diagnosis and management of asthma. National Institutes of Health pub No 97-4051c. Bethesda, MD, National Institutes of Health, 1997.

25. Peters A, Dockery DW, Heinrich J, Wichmann HE. Medication use modifies the health effects of particulate sulfate air pollution in children with asthma. Environ Health Perspect 1993; 105: 430-435.

26. Tager IB, Kunzili N, Lurmann F, Ngo L, Segal M, Balmes J. Methods development for epidemiologic investigations of the health effects of prolonged ozone exposure. Part II: An approach to retrospective estimation of lifetime ozone exposure using a questionnaire and ambient monitoring data (California sites). Research Report Number 81. Cambridge, MA, Health Effects Institute, 1998.

27. Scanell C, Chen L, Aris RM, et al. Greater ozoneinduced inflammatory responses in subjects with asthma. Am J Respir Crit Care Med 1996; 154: 24-29.

28. Balmes JR. The role of ozone exposure in the epidemiology of asthma. Environ Health Perspect 1993; 101: Suppl. 4, 219-224.

29. Frisher TM, Kuehr J, Pullwitt A, et al. Ambient ozone causes upper airways inflammation in children. $\mathrm{Am}$ Rev Respir Dis 1993; 148: 961-964.

30. Health effects of outdoor air pollution. Committee of the Environmental and Occupational Health Assembly of the American Thoracic Society. Am J Respir Crit Care Med 1996; 153: 3-50.

31. Kimber I. Allergy, asthma and the environment: an introduction. Toxicol Lett 1998; 102-103: 301-306. 